\title{
PRÁTICAS TUTORIAS: DIDÁTICA E COMPETÊNCIAS NO ENSINO A DISTÂNCIA
}

CURITIBA/PR MAIO/2018

\author{
Genoveva Ribas Claro - UNINTER - genoveva.c@uninter.com \\ Ana Cristina Lass Stankievicz - Uniandrade - anastankievicz@bol.com.br \\ Dinamara Pereira Machado - UNINTER - dinamara.p@uninter.com \\ Karyn Lianene Texeira - UNINTER - genoveva.c@uninter.com
}

Tipo: Investigação Científica (IC)

Natureza: Relatório Final de Pesquisa

Categoria: Métodos e Tecnologias

Setor Educacional: EDUCAÇÃO SUPERIOR

\begin{abstract}
RESUMO
Este artigo faz uma análise contextual da tutoria em uma Instituição de Ensino Superior que oferece cursos à distância. Tem como objetivo investigar o processo de tutoria do curso de Pedagogia a distância procurando conhecer as dificuldades encontradas e as competências necessárias para 0 exercício da tutoria, atentando para a questão da qualidade dos cursos. Definir competência em cursos de EAD tem prioridade na autonomia dos sujeitos, ou seja, "aprendizagem independente" e mediatizada, num projeto humanizador e não meramente na transmissão de informações. Deve-se entender o sujeito nos cursos de EAD que interage, interpreta e reconstrói a mensagem, subestimar o aluno apenas a ouvinte, receptor da mensagem leva ao conhecimento instrucional e linear que não acrescenta em nada ao aluno e nem ao professor. Sendo assim, é importante refletir sobre a sua qualidade e eficácia no que se refere principalmente à tutoria que tem a função de mediar o conteúdo e a aprendizagem dos alunos. De todos os setores da EAD a tutoria é que vem mais desenvolvendo modelos de aprendizagens integrados com as tecnologias e desenvolvendo novas didáticas. Por meio de uma pesquisa bibliográfica e de campo os tutores entrevistados destacaram o desenvolvimento de competências e habilidades tutoriais como forma de superar as dificuldades encontradas e a necessidade de uma didática própria para os cursos de EAD. Portanto, é na tensão entre as dificuldades e as competências dos tutores que acontece o surgimento do novo fazer pedagógico necessário à educação a distância.
\end{abstract}

Palavras-chave: Palavras-chave: Educação a distância. Qualidade. Tutoria. 


\section{INTRODUÇÃO}

Esta pesquisa tem como tema as "Práticas Tutoriais", pois a tutoria é o método mais utilizado para efetivar a interação pedagógica do sistema de ensino a distância. O apoio tutorial realiza por meio da intercomunicação dos elementos (professor-tutor-aluno) que intervêm no sistema e os reúne em uma função tríplice: orientação, docência e avaliação. A prática tutorial se refere às ações orientadoras, acadêmicas e institucionais, sendo necessário utilizar técnicas motivacionais, conhecimento da andragogia, conhecimentos das psicologia da aprendizagem, além do domínio das comunicações mediadas pelas tecnologias nos ambientes virtuais de aprendizagem.

Percebe-se que estudar a distância exige perseverança, autonomia, metacognigação, capacidade de organizar o próprio tempo, domínio de leitura, interpretação e, o uso da tecnologia, que dependem de fatores internos do aluno, no entanto, para o sucesso dos cursos a distância outros fatores externos são considerados importantes como estímulos, desafios, materiais dialógicos e esquemas desafiadores de estudos, ou seja, deve existir uma didática própria para os cursos de Educação a Distância.

Assim, as instituições de EAD devem ter a preocupação de formar o tutor por meio de cursos de capacitação e promover competências necessárias para que possam desenvolver didáticas estimuladoras e efetivas para a aprendizagem do aluno. Desta a forma, a questão problematizadora está relacionada em investigar: Quais as competências necessárias para o exercício da tutoria nos cursos superiores na modalidade a distância.

A pesquisa tem como objetivo refletir as competências e as práticas tutoriais nos cursos de EAD, para isso será investigado quais os aspectos necessários para desenvolver uma didática que melhore o desempenho das tutorias nas Instituições de ensino superiores, garantido qualidade nos cursos e programas em educação a distância.

\section{METODOLOGIA DE ESTUDO}

A pesquisa, aqui, é concebida como "um procedimento reflexivo sistemático, controlado e crítico, que permite descobrir novos fatos ou dados, relações ou leis, em qualquer campo do conhecimento" (ANDER-EGG apud LAKATOS; MARCONI, 2005, p. 155). Neste sentido, optou-se pela realização de um estudo de caso pelo fato de ser "uma investigação empírico-indutiva, no qual o caso é a unidade significativa do todo, a deter a possibilidade de explicação da realidade concreta" (DINIZ, 1994, p. 50-51). 
A pesquisa quantitativa se justificou pela utilização do levantamento de dados por meio de um entrevista sobre as dificuldades na prática da tutorial que serve para coletar informações de pessoas a respeito de suas ideias, planos, sentimentos, crenças, como também origem social, educacional e financeira (FINK; KOSECOFF, 1998). Essa técnica é apropriada quando o foco de interesse é "o que está acontecendo" ou "como e porque isso está acontecendo" (FREITAS et al., 2000). No estudo em questão a intenção foi determinar as dificuldades que interferem na aprendizagem dos alunos a distância.

\section{O PAPEL DA TUTORIA NA EDUCAÇÃO A DISTÂNCIA}

A Educação a Distância vem crescendo a cada ano e sendo inserida rapidamente nas instituições de ensino superior, comtemplando os cursos a distância, semi presenciais e presenciais. O surgimento cada vez mais de novos cursos em EAD exigem planejamento e práticas pedagógicas condizentes com a autonomia da aprendizagem e na formação de profissionais competentes para o mercado de trabalho e para novas pesquisas. De acordo com Moore (1983, p.137), a:

Educação a distância é uma relação de diálogo, estrutura e autonomia que requer meios técnicos para mediatizar esta comunicação. Educação a distância é um subconjunto de todos os programas educacionais caracterizados por: grande estrutura, baixo diálogo e grande distância transacional. Ela inclui também a aprendizagem.

Quando o autor define a Educação a distância como transacional, ele se refere não apenas uma separação geográfica entre aluno e professor, mas envolve uma série de relações que se estabelecem nesse espaço, constituindo-se em marcante direcionamento pedagógico. Alguns componentes da EAD definem bem essa modalidade: a estrutura dos programas educacionais, a interação entre os alunos, professores e tutores e a natureza e o grau da autonomia do aluno, assim, é fundamental definir um componente pedagógico de forma que as ferramentas escolhidas possam agregar valor na construção de uma "aprendizagem significativa" (AUSUBEL, 1963).

Ao refletir sobre uma didática eficiente para os cursos de EAD como um conjunto de metodologias específicas para a Educação a Distância, pode-se referir a Baradel (2007) que compreender os vários fatores que influenciam diretamente no processo ensinoaprendizagem e na relação professor-aluno, tornando seus fundamentos de grande importância para a prática pedagógica. Freitas (2011), tem a perspectiva de multifuncionalidade do processo de ensino-aprendizagem e articular as dimensões: 
técnica, humana e política, para Braga (2014) a relação humana existente entre professor e aluno é fundamental para a aprendizagem, as relações de proximidade, empatia e significado, dependem da deste processo, do modo como concebem seu papel, o papel dos alunos e como consideram o pensar e o fazer docente no contexto escolar.

$\mathrm{Na}$ modalidade à distância neste novo século a imensa quantidade de recursos disponibilizados possibilita transformações nas formas de aprender e ensinar e nas relações humanas, esses recursos são possíveis pelas tecnologias da informação e comunicação (TIC).

É neste cenário que se situa a ação da tutoria, com a finalidade de fomentar o discente a distância a um ambiente de aprendizagem diferenciado, atendendo sua necessidades individuais. Este é o grande desafio do orientador acadêmico (tutor) lidar com a diversidade e individualidade dos grupos. Conforme cita Martins (2010) o desafio está em manter a motivação intrínseca do desejo que o adulto geralmente apresenta e os processos de ensino e de aprendizagem, que devem estar coerentes com os seus interesses e as suas necessidades.

Assim a tutoria deve organizar conteúdos, proposta de estratégias para o processamento da informação, escolha de atividades e de recursos significativos para a aprendizagem e a elaboração de instrumentos de avaliação coerentes com as concepções didáticas sustentadas. Deve-se provocar a mudança de valores e atitudes dos indivíduos, com ação pedagógica, favorecendo o desenvolvimento da comunidade de forma contínua e permanente. Os orientadores acadêmicos (tutores) devem fazer parte das equipes de trabalho das instituições que não significa estar apenas nos períodos de tutoria. Uma característica dessa forma de educação é sua ênfase na ação social, na qual a educação atua como o princípio dinâmico.

Segundo Martins (2010) os ambientes de aprendizagem com a presença das tecnologias de informação deve propiciar a representação, a articulação entre pensamentos, a realização de ações e reflexões que questionem constantemente as ações e de uma avaliação contínua. A tecnologia traz mudanças no comportamento tanto do professor quanto do aluno, em que este último exige-se mais participação e autonomia sobre sua aprendizagem e do professor maior participação, diálogo, mediação e domínio da tecnologia e das práticas pedagógicas que favorecem a reflexão sobre a sua própria prática, sendo assim, necessário uma reconstrução do conceito de competências. 
As competências são aprendidas desde que se estabeleça uma estreita relação entre o modelo das competências, os conteúdos/saberes, os métodos, os materiais didáticos e as atividades/tarefas. Para isso o ensino deve ser inovador e de qualidade acompanhada por tutores especializados, materiais didáticos dialogicizantes e avaliação formativa, permitindo ao aluno uma atitude ativa e responsável pela sua aprendizagem.

Segundo Medina (2010) a instituição educacional, é uma a organização social cuja tem como responsabilidade capacitar os estudantes para a cooperação e mediação, em que possam analisar criticamente as concepções, crenças e valores, na busca de resoluções de problemas para o mundo ao qual vive. Bem como o professor tem um papel importante no desenvolvimento das competências, devem estar habilitado com as novas tecnologias, abertos a novos paradigmas e que saibam motivar, incentivar a reflexão crítica e a busca de várias soluções aos problemas. Buscar novas formas de comunicar e dialogar. Os alunos devem ser curiosos, motivados, autônomos e possam ter uma interação com o professor-educador. O desafio da ação e do compromisso na solução dos problemas, ao lado da elaboração dos programas mais adequados para superá-los, vai além da interiorização do conteúdo, do significado da sabedoria; compromete a escola na busca de soluções criativas para as situações e os conflitos das organizações e dos seres humanos.

Assim há uma co-aprendizagem do professor com o aluno, em que ambos tem suas próprias experiências, sendo seres holísticos e complexos, portanto precisa ser desenvolvida uma visão sistêmica e aberta. Na modalidade a distância dependem também de administradores, diretores e coordenadores mais abertos, que entendam todas as dimensões que estão envolvidas no processo pedagógico dinâmico e sistêmico que contribuam para um ambiente de maior inovação, intercâmbio e comunicação (MORAN, 2001).

As aulas devem ter planejamento, resoluções de problemas, incentivo a pesquisa e a análise crítica produzindo cidadãos mais conscientes, habilitado, capacitado e disposto a enfrentar e a buscar o conhecimento. Concordando com Belloni (2001, p.39) "exigindo um trabalhador multicompetente, multiqualificado, capaz de gerir situações de grupo, de se adaptar a situações novas, sempre prontas a aprender. Em suma, um trabalhador mais informado e mais autônomo".

A comunicação é um dos aspectos mais importantes nas práticas pedagógicas e didáticas do tutor na educação à distância. Este processo é muito complexo, por ser realizada em espaço virtual, e por meios de comunicação e informação de via dupla. 
A educação a distância o professor está diante de uma multiculturalidade, aluno de diferentes etnias, região e opiniões e ao transmitir a mensagem não

sabe se como os alunos reagem ao que você recebeu, por isso a importância de mecanismo de feedback para certificar se a comunicação foi compreendida

Este feedback é dado pelos tutores dos pólos, aumentando a responsabilidade do tutor de um curso na modalidade a distância, que precisa identificar as emoções e lidar com elas, proporcionando apoio "motivacional para aqueles que precisam, mas também fazer com que todos os alunos sejam o mais independente possível". (LEMOS, 2002, p. 17-18).

Seguindo os princípios do conceito da Zona de Desenvolvimento Proximal de Vygotsky, o tutor é mediador entre o aluno e o conhecimento e colocar-se à disposição do aluno para tudo o que ele precisa é colocar-se a disposição para aquilo que ele ainda não pode fazer por si próprio para aprender com o objetivo que se torne cada vez mais autônomo.

Moore (2007) conceitua que o aluno aprende reagindo aos estímulos programados pelo professor - teoria construtivista, em que o sujeito aprendente desempenha um papel ativo numa interação com o meio ambiente durante a qual constrói o seu conhecimento. Nesse sentido a autonomia do aluno é uma variável diretamente ligada em ensino e aprendizagem, e na interação entre ensino e aprendizagem. Assim professores e tutores não têm o papel de transmitir conhecimentos e sim criar condições para a produção do conhecimento como fomento do diálogo e da análise crítica.

\section{PRÁTICAS TUTORAIS EM EAD E SEUS DESAFIOS}

Foram entrevistados 10 tutores que atuam no curso de Pedagogia, e dentre as perguntas elaboradas, se concentram nas dificuldades encontradas por eles, e outra, as competências necessárias a um bom tutor.

Segundo a faixa etária pode observar que $30 \%$ destes se encontram na faixa etária de 25 a 30 anos, $40 \%$ entre 35 a 40 anos, $20 \%$ acima de 40 anos. Em relação a formação dos tutores, $70 \%$ tem especialização e $30 \%$ mestrado. Questionados sobre qual motivo os levou a atuarem como orientadores acadêmicos a distância (tutor), pode-se verificar que $60 \%$ apontaram a oportunidade de trabalho e $40 \%$ por terem especialização em educação a distância. 
Ao questionar sobre a atuação na tutoria e suas dificuldades, a maioria dos tutores (60\%) apontaram como maior dificuldade a utilização dos recursos didático-midiáticos pelos alunos, por falta de leitura do material solicitado aos alunos, ou ainda, das atividades propostas. por impossibilidade de acesso aos materiais indicados.

Percebeu que a plataforma de aprendizagem deve envolver aspectos pedagógicos e ergonômicos, com fácil acesso, conteúdos planejados, partindo do conceito global e seguindo as conceitos mais específicos, proporcionando os alunos utilizarem de forma sinérgica, para propiciar aprendizagens significativas e prazerosas. Costumam-se considerar, para a avaliação de plataformas para a educação a distância, sete características: interface, navegação, avaliação, recursos didáticos, interação, coordenação e apoio administrativo. O ciberespaço deve ter uma atenção muito especial no contexto de um curso na modalidade a distância, pois será como um ponto de encontro, onde informações imprecisas podem levar a uma série de equívocos e até mesmo à falta de estímulo do aluno para acessá-lo.

O segundo aspecto apontado pelos tutores com $40 \%$ dos apontamentos é a falta de comunicação da coordenação do curso e com o professor da disciplina. O tutor acompanham as orientações da coordenação e do professor, responsáveis pelo planejamento pedagógico, pelo desenvolvimento do conteúdo e pela gestão do processo de avaliação da aprendizagem dos alunos. Dessa forma, a proximidade entre tutor, coordenador e professores deve ser a maior possível.

Outro aspecto apontado por $20 \%$ dos tutores é a pequena procura da tutoria por parte dos alunos do curso tem se constituído em mais uma dificuldade, afinal essa é uma das interações mais privilegiadas do curso, requerendo grande atenção. Alguns tutores descreveram que a grande maioria entra em contato com a tutoria para resolver problemas na plataforma de aprendizagem, informações sobre notas e prazos, sendo poucos que tem uma interação participativa com o tutor.

Outros aspectos apontados pelos tutores foram: A falta de autonomia dos alunos (10\%), perda de prazos (10\%), e estudo dirigido apenas às provas (10\%). Percebe a importância de buscar estratégias pedagógicas para promover a autonomia dos alunos.

A dificuldades de horário e prazos pode ser solucionados com o agendamento de um horário comum ao tutor e ao aluno, a realização de encontros mais curtos e a intensificação do uso das ferramentas de interação assíncronas, por exemplo.

Em relação aos alunos estudarem apenas na véspera das avaliações faz parte de uma 
cultura nas escolas em que os alunos deixam de ter um contato prévio durante o período anterior à avaliação e, quando ela se aproxima, maior interesse para dar conta das dúvidas que surgiram ao longo do curso. A tutoria pode criar estratégias de aprendizagem em que tenha um cronograma de atividades avaliativas durante todo 0 período da disciplina e acompanhado pelo tutor, para auxiliar nos esclarecimentos das dúvidas.

Num processo de aprendizagem o aluno apresenta o sujeito cujo papel é o foco das atenções na atividade, o objeto que o aluno busca é a resolução das tarefas nas atividades, para se chegar ao objeto o aluno utiliza-se de artefatos ou ferramentas, essas ferramentas são utilizados para interagir com a comunidade que é o lócus onde o aluno está inserido e é formada por outros alunos e pelo tutor.

A criação das Comunidades Virtuais possibilita facilitar a comunicação, desenvolve meios para resolver as mais diversas atividades utilizando como recursos a internet. Os vários meios utilizados para a comunicação na aprendizagem são canais de comunicação de mão dupla em que transcendem a função de mediar a interação do aluno com o docente e consequentemente com os outros alunos.

$\mathrm{Na}$ comunidade de aprendizagem em que a tecnologia é utilizada, os alunos precisam conhecer o processo de aprendizagem e sobre si mesmos. É um modelo que exige responsabilidades, planejamento e condução. O planejamento didático, conforme Freitas (1999, apud Barão, 2005), é um processo que envolve operações mentais como: analisar, refletir, definir, selecionar, estruturar, distribuir ao longo do tempo, prever formas de agir e organizar.

São utilizados o material hipertexto e hipermídia, assim como a bibliografia e links disponibilizados e informar ao tutor qual atitude a ser tomada em dado momento da atividade. No ambiente de Aprendizagem On-line, um espaço de liberdade é oferecido aos alunos, onde seu comportamento se modifica. A criatividade e o desejo de "aventurar-se" em fontes de informação e depósitos de saber são estimulados pelo docente. A aquisição de novas competências para trabalhar em grupo, desenvolvendo atitudes como respeito, colaboração e criatividade e proporcionar mudanças no comportamento dos alunos. (BARÃO)

O tutor nos ambiente virtuais deve motivar continuamente os alunos, orientando-os no estudo, estimulando-os nas comunicações formal e informal com os outros membros do ambiente e auxiliando-os na cooperação/colaboração mútua, além de uma equipe transdisciplinar atuando em diversas funções. 
O ambiente virtual deve ser vista como um ambiente rico de idéias, textos, imagens e tratada com responsabilidade e sensibilidade, pois é construída e vivenciada por pessoas; pessoas com sentimentos e objetivos. (BARÃO)

Entende-se que para promover ações em EAD é preciso preocupar-se com três elementos interdependentes: materiais didáticos, a tutoria e a avaliação. Lidar com estes elementos como se fossem "independentes" pode comprometer a ação pedagógica desejada.

\section{CONSIDERAÇÕES FINAIS}

Com a devida pesquisa considera que ao discutir EAD, as questões fundamentais para a competência s e habilidades $d$ tutoria não residem apenas no nível das ferramentas, ou seja, no quanto elas precisam ser transparentes, acessíveis, mas incluir e valorizar a preocupação com os tutores vinculados sempre à concepção pedagógica definida.

Com essa constatação, a tutoria pode promover essa integração, na medida em que a EAD fortalece a necessidade de encontros entre os alunos, envolvendo a todos que tenham interesse num dado tema, independentemente de idade, sexo, proximidade, cultura ou nível educacional, seja em comunidades virtuais ou encontros presenciais, que facilitam a flexibilidade nesta modalidade, respeitando o ritmo e condições do aluno para aprender, isto não quer dizer eliminar objetivos, conteúdos, experimentações, avaliações.

Preparar os recursos humanos para o desenho de um projeto que encontre o aluno onde ele estiver, oferecendo-Ihe todas as possibilidades de acompanhamento, tutoria, material didático e avaliação, permitindo-Ihe construir conhecimentos e saberes, adquirindo hábitos, habilidades e atitudes, de acordo com suas possibilidades, além de abrir espaço para uma representação de estudantes que estudam a distância, de modo a receber feedback e aperfeiçoar os processos.

\section{REFERÊNCIAS}

AUSUBEL, D. P. "The Psychology of Meaningful Verbal Learning". New York: Grune \& Stratton, 1963.

BARADEL, Carina de Barros. Didática: contribuições teóricas e concepções de professores. 2007. 65 fls. Monografia (Graduação em Pedagogia) Universidade Estadual Paulista, Faculdade de Ciências Bauru, 2007. 
BARÃO, Claudio Luiz. Explicitação gráfica de habilidades de tutoria em cursos

mediados por tecnologias de informação e comunicação. Dissertação (Mestrado

em Tecnologia) - Programa de Pós-Graduação em Tecnologia, Centro Federal de

Educação Tecnológica do Paraná, Curitiba, 2005.

BELLONI, Maria Luiza. Educação a Distância. Campinas: Editores Autores Associados, $5^{\mathrm{a}}$ ed, p. 39, 2001.

BRAGA, Osmar Rufino. A relação professor-aluno e o processo de ensinoaprendizagem: um desafio para a ação docente. Ensino Médio em diálogo. Disponível em.http://www.emdialogo.uff.br/content/relacao-professoraluno-e-o-processo-de-ensinoaprendizagem-um-desafio-para-acao-docente. Acesso em: 20 abr. 2014.

FREITAS, Maria Alice Santos de Araújo Costa. Didática, planejamento e avaliação: fascículo de didática. Alegre: FAFIA, 2011.

LEMOS, A. Cibercultura: tecnologia e vida social a cultura contemporânea. Porto Alegre: Sulina, 2002.

MORAN, José Manuel et al. Novas tecnologias e mediação pedagógica. 6. ed. Campinas: Papirus, 2001.

MOORE, M. G. On a theory of independent study. In: SEWART, D.; KEEGAN, D.; HOLMBERG, B. (Ed.). Distance education: international perspectives. Londres: Croom Helm; New York: Routledge, 1983.

MOORE, Michael; KEARSLEY, Greg. Educação a distância: uma visão integrada. (tradução Roberto Galman) São Paulo: Thomson Learning, 2007. 